UDC 54-165:539.12.043

\title{
THE SHORT-RANGE ORDER AND ITS INFLUENCE ON RADIATION STABILITY OF LOW-CONCENTRATION Fe-Cr ALLOYS
}

\author{
P.V. Petrenko, N.P. Kulish, N.A. Mel'nikova*, Yu.E. Grabovskii, T.O. Busko \\ Taras Shevchenko National University of Kiev, Kiev, Ukraine \\ *E-mail: melnikova-43@mail.ru
}

The analysis of the structural phase state of Fe-Cr low concentration solid solutions and steel 1X13, associated with the formation of short-range order (SRO) of various types in them has been performed at the mesoscopic level. A comparison of the SRO and swelling of alloys under irradiation was carried out. It was shown that there is a fairly good qualitative correlation between them.

\section{INTRODUCTION}

An iron-chromium alloys and complex alloyed steels based on them are one of the most priority structural materials for reactors of the next ages [1]. This is primarily due to their high radiation and corrosion resistance and low vacancy swelling.

At the same time, these materials are of great scientific interest, since the nature of the physical processes that determine their indicated properties is not fully understood. Among them, the most important is the high radiation resistance and, as a consequence, the low swelling of low-concentration chromium alloys, whose macroscopically single-phase structure, despite the expected segregation processes, is maintained up to high irradiation fluences.

Highly concentrated austenitic chromium-helium alloys not related to dispersion hardening and some others have similar properties. Moreover, it was found that in some of these alloys the specific volume not only did not increase, but even decreased upon irradiation [2]. It can be assumed that the physical nature of the processes that causes such an unusual behavior of these alloys at irradiation is one and the same.

There are two fundamentally different approaches for explaining the high phase stability andthe small vacancy swelling of the considered alloys, which are usually observed in a certain temperature range [3].

One of them suggests that a change in the structural phase state and radiation resistance of alloys is associated with the influence of irradiation on the energy characteristics and properties of the initial and structural defects under irradiation.

In particular, the possibility of the formation of highintensity sinks of point defects in the form of thermally stable complexes of impurity atoms and vacancies is allowed under irradiation [4]. In the case of a large difference in the sizes of impurity atoms and matrix atoms in a solid, recombination centers of variable polarity [5] and others are formed.

In another, the high stability of alloys upon irradiation is associated with the energy and magnetic state of the entire system, which is determined mainly by the position of the alloy in the state diagram. In particular, it is assumed that a high resistance to radiation swelling of steels, including ferritic iron- chromium, is associated with high thermal and radiation stability of finely dispersed precipitates, which are present in large quantities in the macrostructure. Their appearance is due to ordering, the formation of longrange and short-range order (SRO), K-state, stratification of solid solution, etc. [2, 4, 6].

However, the physical nature and features of the processes under consideration, including segregation processes that affect the stability of these secretions during irradiation, were not analyzed.

It is assumed that the effect of SRO on alloy swelling is associated only with an increase in the formation energies and activation of vacancy migration, which complicates the formation of vacancy pores $[2,7$, 8].

The work systematized the results of experimental studies of the structural-phase state of low-concentration $\mathrm{Fe}-\mathrm{Cr}$ alloys at the mesoscopic level associated with the formation of SRO of various types in them, its change under external influences on the alloys, and the effect of SRO on the swelling of alloys under irradiation.

\section{STRUCTURE OF IRON-CHROME ALLOYS EXPERIMENTAL RESULTS}

A significant number of experimental and theoretical studies are devoted to the study of the structural phase state of iron-chromium alloys. However, the results obtained by different authors differ significantly [9-13]. This is usually associated with the fact that the mobility of atoms below $500{ }^{\circ} \mathrm{C}$ is extremely small. To obtain an equilibrium state at these temperatures, annealing lasting hundreds or even thousands of hours is required. Therefore, in most cases, the studies were performed in alloys characterized by a different metastable state and with a different composition of impurities.

One of the latest phase diagrams of $\mathrm{Fe}-\mathrm{Cr}$ alloys is shown in Fig. 1 [9].

It can be seen that chromium, dissolving in iron, forms continuous solid solutions with a bcc lattice at high temperatures. The assumption of the formation of a long-range solid solution was not confirmed [12]. The $\sigma$-phase is formed from the $\alpha$-solid solution at $830{ }^{\circ} \mathrm{C}$ and a chromium concentration of $\sim 45 \%$. The $\alpha \rightarrow \sigma$ transformation proceeds extremely slowly. The $\sigma$-phase was not detected after annealing the alloys in the range $350 \ldots 550{ }^{\circ} \mathrm{C}$ for tens of hours [14]. 


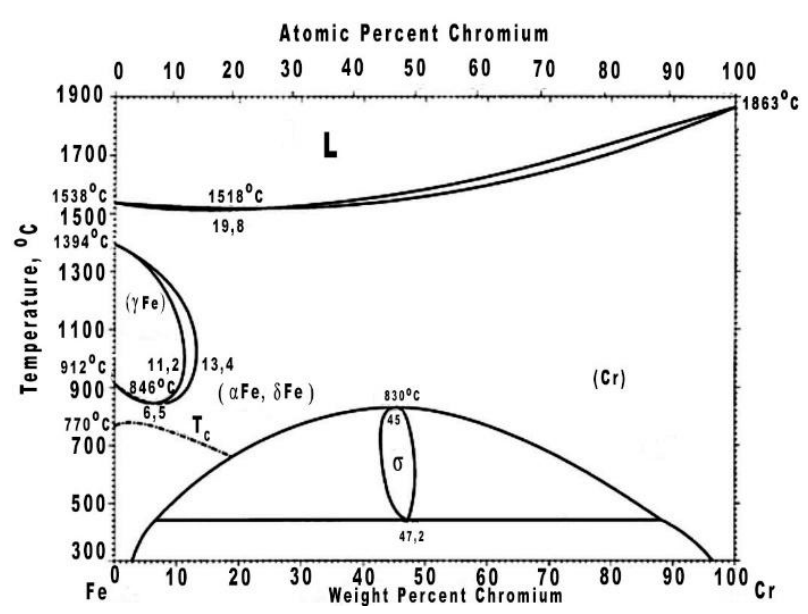

Fig. 1. The state diagram of $\mathrm{Fe}-\mathrm{Cr}$ alloys [9]

The $\alpha$-solid solution and the $\sigma$-phase become unstable and decompose into two bcc solid solutions with different chromium contents, thereby forming equilibrium state of the immiscibility region at the temperature decreases to $440{ }^{\circ} \mathrm{C}$ (according to other sources, $\left.520 \ldots 550^{\circ} \mathrm{C}[10,11,13]\right)$. The separation process begins at a higher temperature at the absence of the $\sigma$-phase in the solid solution $[10,11]$. The delamination process is also slow. The separation process is not completed even after $20 \mathrm{~h}$ of annealing at $T=90{ }^{\circ} \mathrm{C}[15]$. Thus, this process captures a wide range of temperatures and depends on the alloy concentration under real conditions.

Recently, the given state diagram has been criticized from the point of view of the boundaries of the existence of an $\alpha$-solid solution, especially at a low chromium concentration $[13,16,17]$. This is primarily due to the discovery of SRO in alloys [18-20]. The theoretical studies haves how that with the for mation of SRO the free energy of the $\alpha$-solid solution decreases markedly, that will stimulate its existence. As a result, the delamination boundary of low-concentration $\mathrm{Fe}-\mathrm{Cr}$ alloys will shift toward lower concentrations, and its temperature dependence will have a large steepness [17].

For the first time, G. Mirebeau et al. quantitatively studied the nature and degree of SRO of alloys in the concentration range $0<x \leq 15 \% \mathrm{Cr}$, using the most reliable direct method of elastic diffuse scattering of thermal neutrons $[18,19]$.

The results of studies of three alloys containing 5 , 10 , and $15 \% \mathrm{Cr}$ are presented in [18]. Samples for research were thermally processed so that at room temperature the stable structure of the alloys corresponded to $430{ }^{\circ} \mathrm{C}$. The treatment regime was selected by studying the kinetics of alloy ordering by the method of residual electrical resistance. The intensity of diffuse neutron scattering was measured at room temperature in the range of angles $0<\lceil\vec{k}]<0.25 \AA$ between two adjacent structural maxima.

Using the obtained angular dependences, in the usual way [20], the Cowley SRO parameters $\alpha_{1,2}$ averaged for the first two nearest coordination spheres were calculated, which, as the authors write, can be considered with great confidence. These parameters and possible measurement errors are shown in Fig. 2.

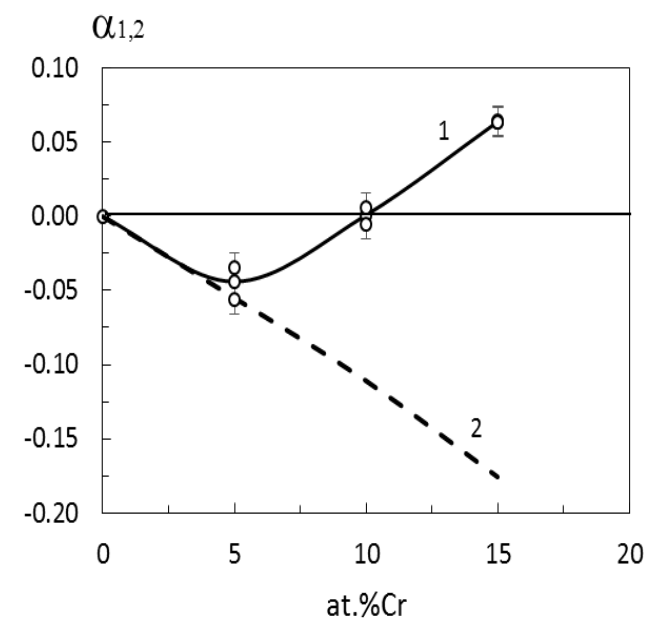

Fig. 2. The concentration dependence of the SRO parameter $\alpha_{1,2}$ for the state of $\mathrm{FeCr}$ alloys at $T \approx 430{ }^{\circ} \mathrm{C}(1)$; calculation by the formula $-x /(1-x)(2)[18]$

The studies were repeated by the same authors on 11 alloys, in nine of which the chromium concentration was $x \leq 10 \%$ in order to clarify the data presented [19]. The alloys were cooled in a quartz tube to $520^{\circ} \mathrm{C}$ after homogenization at $800^{\circ} \mathrm{C}$. Then the temperature was slowly lowered to $430{ }^{\circ} \mathrm{C}$, at which they were held for several hours. The alloy with $15 \% \mathrm{Cr}$ was annealed for 18 and $84 \mathrm{~h}$.

In addition, the measurement procedure was improved the angular dependence of the scattering intensity, which increased the ratio of the intensity of the useful signal to the background by 12 times in comparison with [18]. This allowed calculating the parameters of the SRO parameters for five coordination spheres with sufficient accuracy. A characteristic feature of the angular dependences of the diffuse scattering intensity given in $[18,19]$ is that the scattering intensity at $[\vec{k}] \rightarrow 0$ tends to 0 and to a maximum for $x<10 \%$ and $x>11 \% \mathrm{Cr}$ alloys, respectively.

This indicates that in alloys with a concentration of less than $10 \% \mathrm{Cr}$ at $430{ }^{\circ} \mathrm{C}$ the resulting $\mathrm{SRO}$ is negative, and in more concentrated alloys SRO is positive. The diffuse scattering intensities coincide with the Laue background in alloys with 10 [18] and $11 \% \mathrm{Cr}$ [19].

The SRO parameter $\alpha_{1,2}$ of alloys with $x<10 \% \mathrm{Cr}$ is negative, and that of alloys with $x>11 \% \mathrm{Cr}$ is positive at $T=430{ }^{\circ} \mathrm{C}$, i.e. at $x \cong 10 \ldots 11 \% \mathrm{Cr}$, the sign of the SRO parameter $\alpha_{1,2}$ averaged over the volume of the alloy is inverted. Does this mean that an inversion of the SRO type occurs at a concentration of $10 \ldots 11 \% \mathrm{Cr}$ ? As will be shown in the future, such a conclusion cannot be drawn.

The short range order in $\mathrm{Fe}-\mathrm{Cr}$ alloys was also studied by Mössbauer spectroscopy [21-23]. The results of studies of alloys containing 3.8, 8.7, and $16.2 \% \mathrm{Cr}$ are presented in [21]. The alloy samples were deformed by rolling $(\sim 85 \%)$ and then annealed in an oil-free vacuum at $830^{\circ} \mathrm{C}$ for $4 \mathrm{~h}$ in a quartz tube and then 
cooled together with the tube in air (initial state). Then they were annealed sequentially at $430{ }^{\circ} \mathrm{C}$ for $6 \mathrm{~h}$ and $400{ }^{\circ} \mathrm{C}$ for $40 \mathrm{~h}$.

The average population of chromium atoms of the first and second coordination spheres with respect to the iron atom was determined. We calculated the SRO parameters $\alpha_{1,2}$, using these data. These parameters of $\mathrm{Fe} 3.8 \mathrm{Cr}$ and $\mathrm{Fe} 16.2 \mathrm{Cr}$ alloys in the initial state turned out to be equal to -0.053 and +0.096 , respectively, which coincides with the previous results [18]. Additional annealing of alloys at 430 and $400{ }^{\circ} \mathrm{C}$ did not change the degree of ordering. SRO was not detected in the Fe8.7Cr alloy.

The ordering of these alloys at lower temperatures was also studied. In order to stimulate the ordering processes, the alloys after additional annealing were irradiated with electrons $E=5.5 \mathrm{MeV}$ and a beam density of $7 \cdot 10 \mu \mathrm{A} / \mathrm{cm}^{2}$ with fluences of $10^{18} \mathrm{~cm}^{-2}$ and $2 \cdot 10^{18} \mathrm{~cm}^{-2}$ at $100{ }^{\circ} \mathrm{C}$. After $\mathrm{Fe} 3.8 \mathrm{Cr}$ alloy irradiation, the $\alpha_{1,2}$ parameter increased to -0.105 and -0.132 , respectively, which significantly exceeds the maximum value for homogeneous ordering. After irradiating the Fe16.2Cr alloy with a fluence of $10^{19} \mathrm{~cm}^{-2}$, the $\alpha_{1,2}$ parameter, remaining positive, increased to +0.127 , which is lower than the maximum possible value with uniform SRO.

In addition, the mechanism of SRO processes was studied. It comes down to the spatial redistribution of atoms in several coordination spheres closest to the central atom. Therefore, the rate of ordering in the processes under consideration is large.

It was reported in [22] that the $\mathrm{Fe} 15.7 \mathrm{Cr}$ alloy annealed at $800{ }^{\circ} \mathrm{C}$ for $4 \mathrm{~h}$ and cooled with the tube was irradiated with electrons $E=5.5 \mathrm{MeV}$ with a fluence of $10^{19} \mathrm{~cm}^{-2}$ at 100,50 , and $0^{\circ} \mathrm{C}$. In the case of an un irradiated alloy, $\alpha_{1,2}=+0.024$, and after irradiation at $100{ }^{\circ} \mathrm{C}, \quad \alpha_{1,2}=+0.120$, which coincides with the previous result. The parameters $\alpha_{1,2}$ after irradiation of the alloy at 50 and $0{ }^{\circ} \mathrm{C}$ were found to be +0.044 and +0.034 , respectively.

The study of the temperature dependence of the SRO parameter $\alpha_{1,2}$ in the temperature range $400 \ldots 1050{ }^{\circ} \mathrm{C}$ on quenched samples of 1 X13 steel are presented in [23]. It was shown that with increasing temperature in the $400 \ldots 750{ }^{\circ} \mathrm{C}$ region, at which the equilibrium state of steel was fixed by quenching, the SRO is positive and $\alpha_{1,2}$ decreases linearly. A similar temperature dependence of $\alpha_{1,2}$ is observed for the $15.7 \% \mathrm{Cr}$ alloy.

The effect of irradiation on the ordering nature of the Fe15.7Cr alloy and 1X13 steel was studied under irradiation temperatures close to the transformation temperature $\alpha \rightarrow \alpha+\alpha^{\prime}$ [23]. Firstly, the state of the alloy is very sensitive to small changes in temperature, and, secondly. This change has an anomalous character. So, under irradiation of the $\mathrm{Fe} 15.7 \mathrm{Cr}$ alloy with electrons $E=5.5 \mathrm{MeV}$ with a fluence of $10^{18} \mathrm{~cm}^{-2}$ at $T=350{ }^{\circ} \mathrm{C}$ $\alpha_{1,2}=0.032 ; \quad T=450{ }^{\circ} \mathrm{C} \quad \alpha_{1,2}=0.066 ; \quad T=500{ }^{\circ} \mathrm{C}$ $\alpha_{1,2}=0.008$, and $T=550^{\circ} \mathrm{C} \quad \alpha_{1,2}=0.050$. Those irradiation at $500{ }^{\circ} \mathrm{C}$ leads to a drop in the $\alpha_{1,2}$ alloy to almost zero.
A similar dip of the $\alpha_{1,2}$ parameter is also observed under irradiation of $1 \mathrm{X} 13$ steel at the same conditions: $T=350{ }^{\circ} \mathrm{C} \quad \alpha_{1,2}=0.125 ; \quad T=450{ }^{\circ} \mathrm{C} \quad \alpha_{1,2}=0.123$; $T=500{ }^{\circ} \mathrm{C} \quad \alpha_{1,2}=0.06 ; T=550{ }^{\circ} \mathrm{C} \quad \alpha_{1,2}=0.124$. Thus, the degree of ordering reaches a value close to zero at the irradiation of the $\mathrm{Fe} 15.7 \mathrm{Cr}$ alloy and $1 \mathrm{X} 13$ steel at $T=500{ }^{\circ} \mathrm{C}$. In the initial state the alloy and steel after annealing for $30 \mathrm{~min}$ at $1050{ }^{\circ} \mathrm{C}$.

Together with the pipe were cooled in water and then annealed at $750{ }^{\circ} \mathrm{C}$ for $60 \mathrm{~min}$. Note that according to Fig. 2, in quasi-thermal equilibrium at $T=430{ }^{\circ} \mathrm{C}$, the SRO parameter of this alloy is $\alpha_{1,2}=0.073$ [18], and for $1 \mathrm{X} 13$ steel, which includes 0.7 at. $\% \mathrm{C}$ and 1.99 at.\% of other impurities, $\alpha_{1,2}=0.152$ [23].

Thus, impurities almost double the degree of steel ordering compared to alloy. It should also be noted that a large difference between the SRO parameters of the alloy and steel with the same or similar chromium content in the initial state and after irradiation remains. This indicates that impurities in low-alloy $\mathrm{Fe}-\mathrm{Cr}$ alloys stimulate the formation of SRO not only in the initial state, but also after irradiation.

The SRO-parameters $\alpha_{1,2}$ after irradiation below and above $500{ }^{\circ} \mathrm{C}$ in both cases practically coincide. The indicated feature of the structural state of such $\mathrm{Fe}-\mathrm{Cr}$ alloys obtained under irradiation at $T=500^{\circ} \mathrm{C}$ is also observed for neutron scattering.

The character of short-range ordering during prolonged annealing in the temperature range $400 \ldots 600{ }^{\circ} \mathrm{C}$ was studied in $x=10 \ldots 25 \% \mathrm{Cr}$ alloys by the neutron diffraction method near $[\vec{k}]=0$ in $[14,15]$. The alloys were annealed at $900 \ldots 950{ }^{\circ} \mathrm{C}$ for $1 \ldots 2 \mathrm{~h}$ and quenched in water. Then, they were annealed at temperatures from 400 to $600{ }^{\circ} \mathrm{C}$ from 4 to $200 \mathrm{~h}$. The diffuse maximum was typical in the neutron diffraction patterns at $[\vec{k}]=0$, which is typical for alloys that are closely ordered by type $\alpha_{1,2}>0$ for all alloys, regardless of heat treatment.

In the case of $\mathrm{Fe} 9.75 \mathrm{Cr}$, its size and shape during four-hour annealing in the temperature range $400 \ldots 600{ }^{\circ} \mathrm{C}$ remained unchanged and coincided with the results obtained in the initial state upon quenching.

The small-angle scattering due to the formation of small clusters was superimposed on this maximum for alloys with a high chromium content upon annealing. Thus, upon annealing at $T=450{ }^{\circ} \mathrm{C}$ of the $\mathrm{Fe} 19.7 \mathrm{Cr}$ alloy, a slight increase in the maximum occurs, similar to that observed during annealing at $T=430{ }^{\circ} \mathrm{C}$ of the $\mathrm{Fe} 15 \mathrm{Cr}$ alloy [19]. The diffuse maximum substantially increased at $T=500{ }^{\circ} \mathrm{C}$, and at the same time, its shape changes.

The latter effects significantly increased during annealing for $24 \mathrm{~h}$. At the same time, annealing the alloy at temperatures of 400,550 , and $600{ }^{\circ} \mathrm{C}$ for $4 \mathrm{~h}$ does not change the scattering intensity observed for the alloy quenched in the initial state.

So, low-concentration $\mathrm{Fe}-\mathrm{Cr}$ solid solutions are heterogeneous at the mesoscopic level. The short-range order is formed in them, the structure of which is different in different concentration and temperature regions. 


\section{DISCUSSION}

a). Alloys containing $1 \ldots 5 \% \mathrm{Cr}$.

In these alloys, the SRO is negative and the parameter $\alpha_{1,2}$ in absolute value increases with the concentration of chromium. This dependence is close to the straight line $\alpha_{1,2}=-x /(1-x)$, characteristic of the maximum degree of uniform ordering of a solid solution (see Fig. 2, curve 2).

Consequently, the attractive forces between the nearest heterogeneous alloy atoms are greater than those with single-sort atoms. Apparently, this nature of the interaction is also characteristic of atoms more distant from each other, since in the alloys, regardless of concentration, in the third coordination sphere, the distribution of atoms is also ordered by the $\alpha_{3}<0$ type. At the same time, the averaged SRO $\alpha_{4,5}$ parameter equal zero for the fourth coordination sphere, whose radius is $R_{4}=1.66 a$ and for the fifth $R_{5}=1.73 a$, where $a$ is the lattice parameter [19].

Consequently, the size of closely ordered alloy clusters will be less than 1-2 lattice parameters. The SRO becomes local upon prolonged annealing or at irradiation. Cluster sizes increase significantly and they can already be observed by probe methods $[13,25]$.

As far as we know, there is no reliable information about the structure of closely ordered clusters. In fact, the solid solution, in which local SRO was observed, is heterogeneous at the mesoscopic level. It contains microregions (clusters) not only enriched with atoms of the alloying element, but also with a different spatial arrangement of atoms than that of the matrix.

In the case of a negative SRO, the structure of these configurations will be similar to the distorted atomic configuration of the superstructure, since with its development, the local SRO turns into a distant one or the solid solution decomposes with the formation of an intermetallic phase adjacent to the solid solution. Not that, not another in these alloys was not observed. The $\sigma$ phase in terms of chromium concentration is very far from the alloys under consideration. Therefore, the resulting clusters are likely to have a distorted symmetry of the superstructure, the Curie temperature of formation of which is very low.

b). Alloys with $5 \ldots 11 \% \mathrm{Cr}$.

The negative SRO in the alloys is preserved in this concentration range at $T=430^{\circ} \mathrm{C}$. But it is surprising that with an increase in the chromium concentration in the alloy, $\alpha_{1,2}$ decreases, and $\alpha_{1,2}$ is equal to zero at $x \cong 10 \ldots 11 \% \mathrm{Cr}$. The latter indicates that near the concentration of $10 \% \mathrm{Cr}$, atoms are randomly distributed over the lattice sites of the alloy. However, as was shown earlier $[14,15]$ and in experiments using probe methods [13, 26], it was shown that with prolonged annealing or upon irradiation at $430{ }^{\circ} \mathrm{C}$ in alloys, including those with $x=9 \ldots 11 \% \mathrm{Cr}$, precipitates are enriched in chromium. That is, in these alloys a local SRO is observed, which is in clear contradiction with the previous experimental result.

In our opinion the nature of this contradiction is associated with a change in the nature of the interaction forces between atoms, and consequently, in the ordering of alloys, the chromium concentration of which is above
$5 \%$. First, with an increase in chromium concentration, the band structure of the alloy changes. In particular, the formation of SRO in the alloy is accompanied by a noticeable decrease in the density of electronic states at the Fermi level [27]. The forces of electronic interaction between atoms, determined by the position of the Fermi level in the electron band, will change not only in magnitude but also in sign $[18,19,28]$.

Secondly, a decrease in the distance between chromium atoms increases the magnetic interaction between the magnetic moments of chromium and iron atoms, as a result of which attractive forces arise between chromium atoms [13]. Therefore, in alloys with $x>5 \% \mathrm{Cr}$, the negative SRO caused by the attractive forces between different types of atoms, reaching a maximum value at $x \cong 5 \% \mathrm{Cr}$, becomes unstable and begins to collapse. At the same time, clusters are formed whose structure corresponds to a positive SRO. Thus, in these alloys, as in a number of others (Ni-Fe, Ni-Mn, $\mathrm{Fe}-\mathrm{Al}, \mathrm{Pt}-\mathrm{Co}$ ), clusters coordinated by different types coexist simultaneously.

The established degree of order will come when the rate of disordering of some clusters and the rate of ordering of others are equal. Its value is determined by the temperature and concentration of the alloy. The average degree of SRO equal to zero is observed in the alloy with $x \sim 10 \% \mathrm{C}$ rat $T=430{ }^{\circ} \mathrm{C}$.

Since the temperature regions of existence of SROs of different types differ, at other temperatures this concentration will be different. Undoubtedly, this process will be affected by radiation.

c). Alloys containing morthan $11 \% \mathrm{Cr}$.

The SRO parameter $\alpha_{1,2}$ is positive eat $T=430{ }^{\circ} \mathrm{C}$ in these alloys and in the Fe11.8Cr alloy $\alpha_{1,2}$ is +0.012 . With an increase in the concentration of chromium in the alloy, it increases and at $15 \%$ it reaches +0.064 . Unlike alloys with $x=1 \ldots .5 \% \mathrm{Cr}$, in which the SRO was uniform at $430{ }^{\circ} \mathrm{C}$ and the parameter $\alpha_{1,2}$ is close to the maximum possible value, in the considered alloys it is much less than this value $\left(\alpha_{1,2}\right)_{\max }=0.176$. Moreover, as was shown earlier, with other treatments, including after irradiation, the situation was similar. So, upon irradiation of the $\mathrm{Fe} 15.7 \mathrm{Cr}$ alloy at $T=100^{\circ} \mathrm{C}$ with electrons with a fluence of $10^{19} \mathrm{~cm}^{-2}-\alpha_{1,2}=+0.120$, and of the Fe16.2Cr alloy with a fluence of $10^{19} \mathrm{~cm}^{-2}$ $-\alpha_{1,2}=+0.127$. Consequently, these alloys, like the $\mathrm{Fe} 15 \mathrm{Cr}$ alloy, seemingly are ordered uniformly. However, studies by probe methods of annealed for a relatively long time or irradiated alloys revealed the presence of chromium-enriched precipitates of unknown structure $[13,26,29,30]$. Those SRO is local in them. Thus, precipitates with an average radius of $1.16 \mathrm{~nm}$ and a total volume of 5.5 and $49.3 \%$ chromium concentration are observed in the $\mathrm{Fe} 15 \mathrm{Cr}$ alloy irradiated at $300{ }^{\circ} \mathrm{C}$ with electrons $E=1 \mathrm{MeV}$ and $0.012 \mathrm{dpa}$ (displacements per atom). The average precipitate radius is $2.9 \mathrm{~nm}$, the total volume is $6.7 \%$, the chromium concentration in them is $96 \%$, and in the matrix it is 8.8 at.\% a fluence of $0.7 \mathrm{dpa}$ [30].

It can be assumed that a negative SRO remains in the alloys under consideration, which compensates for a partially positive SRO. Indeed, as can be seen from the above example of the $\mathrm{Fe} 15 \mathrm{Cr}$ alloy, only $6.7 \%$ of the 
total volume after chromium irradiation with $0.7 \mathrm{dpa}$ is enriched in precipitates. The remaining $93.3 \%$ of the volume is a solid solution depleted to $8.8 \% \mathrm{Cr}$, which is most likely ordered by negative type.

The formation of SRO in Fe-Cr alloys is carried out by two mechanisms. As indicated earlier, the formation of SRO is due to the redistribution of atoms in the nearest coordination spheres upon short-term annealing. In this case, the SRO formation rate is rather large, since in this case atom migration over large distances is not required. Apparently, this mechanism transforms one type of SRO into another in clusters. The second mechanism is associated with the migration of atoms over long distances. It takes place upon prolonged annealing and especially upon irradiation.

Irradiation, depending on its conditions, will both destroy order in alloys due to displacements of atoms from lattice sites and uncorrelated recombination of vacancies and interstitial atoms, and contribute to their ordering due to radiation-enhanced diffusion. The contribution of each of these processes to ordering is determined by the temperature, the rate of formation of radiation defects, and the fluence of irradiation of the alloy. In addition the structural-phase state of solid solutions will be affected by noequilibrium segregations formed upon irradiation, the driving force of which is kinetic processes.

When studying segregation processes in lowconcentration $\mathrm{Fe}-\mathrm{Cr}$ alloys, results were obtained that are difficult to explain in the framework of the mechanisms proposed in the literature. Thus, upon irradiation of $\mathrm{Fe} 2.8 \mathrm{Cr}$ alloys $T=600{ }^{\circ} \mathrm{C}$ [25], $\mathrm{Fe} 9 \mathrm{Cr}$, $T=450{ }^{\circ} \mathrm{C}$ [32], and $\mathrm{Fe} 13 \mathrm{Cr}, T=525^{\circ} \mathrm{C}$ [33], the grain boundaries are enriched with chromium. The grain boundaries of chromium are depleted at irradiation temperature of $400{ }^{\circ} \mathrm{C}$ of $\mathrm{Fe} 13 \mathrm{Cr}$ and $\mathrm{Fe} 5 \mathrm{Cr}$ alloys [33]. When $\mathrm{Fe}-\mathrm{Cr}$ alloys are irradiated at temperatures above and below the transformation temperature $\alpha \rightarrow \alpha+\alpha^{\prime}$, the direction of fluxes of chromium atoms with respect to the grain boundary has different signs. Since the difference in irradiation temperature is small, it is impossible to explain the above results by a change in the transport mechanism. The main reason for the observed results, in our opinion, is the influence on the segregation processes of the forces of thermodynamic interaction between the atoms of the alloy, which is the cause of SRO [20]. This interaction upon irradiation will determine the direction of atomic fluxes that will stimulate the ordering processes - disordering of the alloy characteristic of these irradiation conditions. Upon low-temperature irradiation, the direction of flow of chromium atoms will be such that, along with accelerated diffusion, it stimulates the formation of a SRO existing in the alloy, i.e. from borders to the volume of grains. This result was obtained at irradiating by electrons with fluence of $10^{18}$ and $10^{19} \mathrm{~cm}^{-2}$ at 100 and $150{ }^{\circ} \mathrm{C}$ iron alloys containing $3.8,16.2 \% \mathrm{Cr}$ [21] and an alloy with $15.7 \% \mathrm{Cr}$ irradiated at $100{ }^{\circ} \mathrm{C}$ with a fluence of $10^{18} \mathrm{~cm}^{-2}$ [22]. Apparently, this also explains the enrichment of intragranular so-called preferential effluents with chromium observed by many authors upon irradiation of alloys [1].
In alloys with a chromium concentration of less than $5 \%$, the negative SRO, and in alloys with a high chromium content, a positive SRO become thermodynamically unstable at irradiation temperatures above the transition temperature $\alpha \rightarrow \alpha+\alpha^{\prime}$. The decay of chromium-rich clusters in one and the other case will cause the escape of chromium atoms from the volume of grains of the alloy to extended sinks. It is possible that the low-temperature radiation embrittlement observed in $\mathrm{Fe}-\mathrm{Cr}$ alloys is also associated with these processes.

Irradiation of $\mathrm{Fe}-\mathrm{Cr}$ alloys, like other alloys in which different types of SROs are observed [20, 34], does not affect the nature of ordering. However, in this case, the steady state degree of order, including the inversion of $\alpha_{1,2}$, will be determined not only by the concentration and temperature of the solid solution, but also by the intensity and fluence of the irradiation.

It follows from the considered results that in the state of the so-called stratification, low-concentration $\mathrm{Fe}-\mathrm{Cr}$ alloys consist of a depleted bcc solid solution ordered by type $\alpha_{1,2}<0$, in which clusters enriched in chromium formed on the basis of the matrix are interspersed and ordered by type $\alpha_{1,2}>0$. The volumes ratio of differently ordered regions, the sizes of ordered clusters, the degree of their enrichment and ordering in a quasiequilibrium state is determined by the concentration, temperature, and type of processing of the alloy. Naturally, in this case, on the state diagram, a clear boundary of the existence of one and the other types of ordering, as well as the boundaries of the separation of Fe-Cr alloys, will not be observed.

\section{SHORT ORDER AND SWELLING OF ALLOYS}

The influence mechanism of SRO on the swelling of alloys at irradiation, proposed by the authors, was described earlier in $[35,36]$. Briefly it comes down to the following. The formation of SRO in a solid solution is accompanied by the appearance of elastic correlated atomic displacements from the sites of the crystal lattice, determined by linear and quadratic parameters of the size effect. The magnitude and sign of the dimensional effect obtained from the analysis of the experimentally measured angular dependence of the intensity of diffuse scattering of X-rays or neutrons are determined by the signs and magnitude of the SRO parameters and the difference in the sizes of the atoms of the solvent and the doping element (dimensional factor). In the formation of the local order, which is observed in the vast majority of solid solutions upon irradiation, displacements are superimposed on these displacements due to the difference in the specific volumes formed on the basis of the lattice of the cluster matrix and the matrix itself. Naturally, the resulting fields of elastic displacements will interact with radiation defects, thereby creating alternative centers for the capture of radiation defects in solid solutions, at which they will annihilate by mutual recombination. Depending on the sign of stress, they will capture either vacancies or internodes. These centers are not associated with any lattice defects and, therefore, they are homogeneously distributed in the alloy bulk with a 
high density. Therefore, even in the case of a small difference between the sizes of the atoms of the legant and the matrix, their contribution to the annihilation of radiation defects will be large, and in the case of a low density in alloys of extended sinks, it will be decisive. In addition, clusters formed in the SRO will make it difficult to crawl dislocations, preventing a decrease in the concentration of interstitials in alloys.

The results of studies of the swelling of ironchromium steels and alloys upon irradiation are presented in much literature. However, there is no systematic information about swelling, as well as ordering upon irradiation. There is no data on the effect of reactor irradiation on sequencing. Therefore, it is necessary to compare the results obtained in spot studies on samples, possibly of different composition and undergoing various processing.

As an example in Fig. 3 [37], generalized concentration dependences of swelling (neutron irradiation up to doses of $30 \mathrm{dpa}$ ) at different temperatures are shown. It can be seen that in the $400 \ldots 600^{\circ} \mathrm{C}$ temperature range and $2 \ldots 15 \% \mathrm{Cr}$ concentrations, the swelling of the alloys is small in the range of $0.01 \ldots 0.25 \%$. The increase of the irradiation fluence to $148 \mathrm{dpa}$ of alloys with 12 and $17 \% \mathrm{Cr}$ in the same temperature range does not change the indicated swelling limits [3]. Note that this is the temperature range at which SRO is observed in alloys.

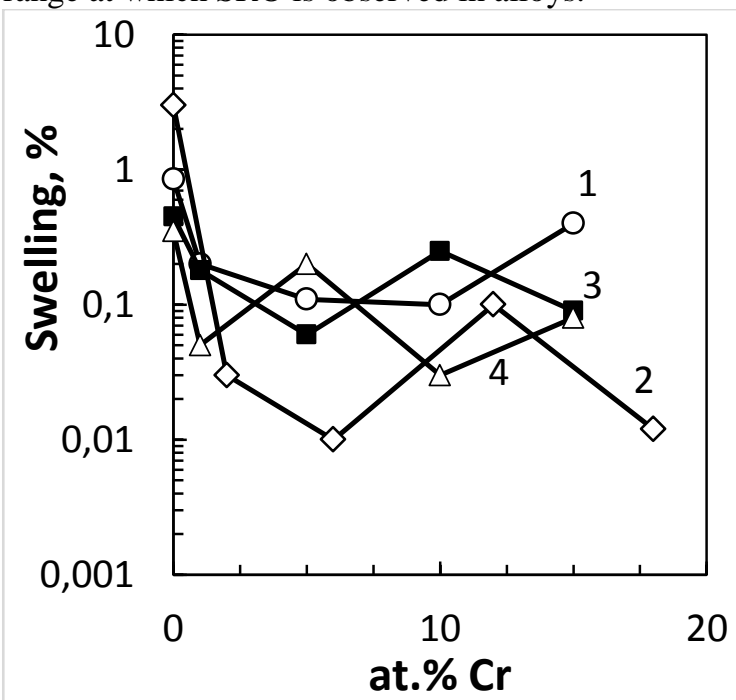

Fig. 3. Concentration dependences of $\mathrm{Fe}$-Cr alloys swelling at different temperatures [37]: $1-380 ; 2-400 ; 3-460 ; 4-615^{\circ} \mathrm{C}$,

the swelling value for pure iron at $T=615^{\circ} \mathrm{C}$ [4]

The addition of chromium to iron in the $1 \ldots 6 \%$ range sharply reduces the alloys swelling at all irradiation temperatures. The smallest swelling is observed in the $\mathrm{Fe} 6 \mathrm{Cr}$ alloy at $400{ }^{\circ} \mathrm{C}$. As was shown earlier (see Fig. 2), a negative SRO forms in these alloys, the maximum degree of which is observed in the Fe5Cr alloy at $T=430{ }^{\circ} \mathrm{C}$ (close to $400{ }^{\circ} \mathrm{C}$ ).

With a further increase in the chromium concentration in the alloy, the swelling increases and reaches the maximum value at $x=10 \ldots 13 \% \mathrm{Cr}$ at 400 and 460 , close to $430{ }^{\circ} \mathrm{C}$. The SRO parameter $\alpha_{1,2}$ decreases and becomes equal to zero at $x=10 \ldots 11 \% \mathrm{Cr}$ at $T=430{ }^{\circ} \mathrm{C}$ and chromium concentration above $6 \%$.
With the chromium content in the alloy above the inversion point, a positive SRO will prevail, the value of which increases with increasing chromium concentration (see Fig. 2). Therefore, the alloy swelling at irradiation decreases.

Thus, a comparison of the SRO $\alpha_{1,2}$ parameter (see Fig. 2) and the swelling (see Fig. 3) of the alloys measured at close temperatures shows that they qualitatively correlate quite well with each other. It follows that the sharp increase in the resistance to swelling of iron with the addition of chromium in the $0 \ldots 6 \%$ range is unambiguously due to the formation of a negative $\mathrm{SRO}$ in $\mathrm{Fe}-\mathrm{Cr}$ alloys. The last was observed by many authors and could not be explained.

There may be doubt about the correctness of the comparison of these data, since at the final stage the alloys in different studies were subjected to different processing. Such a qualitative comparison is quite acceptable, since irradiation, as was shown earlier, does not change the nature of the ordering of iron-chromium alloys. The results of the swelling of $\mathrm{Fe}-\mathrm{Cr}$ alloys near $500{ }^{\circ} \mathrm{C}$, at which a deep minimum is experimentally observed upon irradiation at a temperature dependence of $\alpha_{1,2}$ are of considerable interest.

In Fig. 3 there is no data on the swelling of $\mathrm{Fe}-\mathrm{Cr}$ alloys at this irradiation temperature. Meanwhile, in the temperature dependence of the swelling of alloys near $500{ }^{\circ} \mathrm{C}$, a rather broad maximum is observed. The maximum value significantly exceeds the limit given in Fig. 3. The maximum position on the temperature scale and its value depend on the composition of the alloy and the irradiation conditions [1]. Fig. 3 shows that even at $T=460{ }^{\circ} \mathrm{C}$ the $\mathrm{Fe} 10 \mathrm{Cr}$ alloy swelling is much greater than at other temperatures. And the maximum swelling of the $\mathrm{Fe} 12 \mathrm{Cr}$ alloy of $1.2 \%$, irradiated with $\mathrm{Cr}^{+}$ions at a dose of $100 \mathrm{dpa}$, is observed at $T=500{ }^{\circ} \mathrm{C}$ [1].

It is easy to see that in this case there is a fairly good correlation between the swelling value and the degree of SRO of the alloys under consideration.

In addition, the mechanism of the influence of small additives of impurities, including carbon, on the increase in the resistance to swelling of steels based on iron and iron-chromium alloys becomes clear. It has been repeatedly noted in the literature that impurities affect swelling only when they are in solid solution and in a certain temperature range.

The reason for this is that impurities, as can be seen in the example of 1X13 steel, can significantly increase the degree of BP established during irradiation and change the temperature range of its existence. Naturally, at an irradiation temperature above the disordering temperature of the alloy, the effect of impurities on the swelling will not be observed.

\section{CONCLUSION}

The low-concentration macroscopically single-phase $\alpha$-solid solutions of iron-chromium at the mesoscopic level are stratified with the formation on the basis of a matrix lattice ordered by a negative local type of shortrange order, enriched with chromium microregions (clusters) ordered by the type of positive SRO. The Cowley SRO $\alpha_{1,2}$ parameter averaged over the volume of the alloy is determined by the ratio between the 
sizes, degree of ordering and clusters volumes ordered by different types and depends on the concentration and temperature of the alloy. The transformation of one type of order into another, caused by the disordering of one type of cluster and the ordering of others, occupies a wide concentration and temperature region. The inversion of the SRO parameter of the alloy during such transformation will occur when the rates of the indicated transformations become equal. Thus, the inversion of the sign of the SRO $\alpha_{1,2}$ parameter does not mean that this is due to the inversion at this point of the SRO type.

A comparison of the SRO $\alpha_{1,2}$ parameter with the swelling value of the iron-chromium alloys and 1X13 steel shows that a fairly good qualitative correlation is observed between them. With an increase in the degree of ordering, regardless of its type, the swelling decreases. A sharp decrease in swelling upon doping of iron with chromium $(x<6 \%)$, which could not be unambiguously explained, is due to the formation of a negative SRO in the alloy. A significant decrease in the 1X13 steel swelling compared with an alloy of the same composition is due to the fact that impurities in the steel double the degree of ordering.

\section{REFERENCES}

1. V.N. Voyevodin, I.M. Neklyudov. The evolution of structural phase states and radiation resistance of structural materials. Kiev: "Naukova dumka", 2006, $376 \mathrm{p}$.

2. A.M. Parshin. Structure, strength and radiation damage of corrosion-resistant steels and alloys. Chelyabinsk: "Metallurgy", 1988, 656 p.

3. V.F. Zelensky, I.M. Neklyudov, T.P. Chernyaeva. Radiation defects and swelling of metals. Kiev: "Naukova dumka", 1988, 296 p.

4. Yu.V. Konobeev. Vacancy swelling of metals and alloys // Problems of Atomic Science and Technology. 1984, N 1(29), p. 172-186.

5. A.S. Bakay, V.F. Zelensky, I.M. Neklyudov. Centers of recombination of point defects in alternating polarity // Problems of Atomic Science and Technology. 1986, N 1(38), p. 3-6.

6. A.M. Parshin, I.A. Povyshaev. Features of forced recombination of radiation defects in chromium ferritic steels // Metals. 1994, N 6, p. 48-52.

7. A.A. Kuznetsov, I.P. Kursevich, V.A. Nikolaev, V.V. Rybin, A.N. Lopatin. Radiation swelling of high nickel alloys prone to short range ordering // Radiation Materials Science. Proceedings on Radiation Material Science. Alushta, May 22-25, 1990, v. 2, p. 117-125.

8. I.A. Akhiezer, L.N. Davydov. A relation between the ordering tendency and magnitude of void swelling of alloy // J. Nucl. Mater. 1981, v. 26, N 1-2, p. 115117.

9. ASM Metals Handbook. Desk Edition. V. 3. Alloy Phas. Diagrams. ASM International the Materials Information Company, 1992, p. 662.

10. O. Kubashevsky. State diagrams of binary systems. M.: "Metallurgy", 1985, 184 p.

11. O.M. Barabash, Yu.N. Koval. The crystalline structure of metals and alloys. Directory. Kiev: "Naukova dumka", 1986, 599 c.
12. E.Z. Vintaykin, Yu.V. Kolontsov, E.A. Medvedev. The low-concentration part of the $\mathrm{Fe}-\mathrm{Cr}$ state diagram // Izv. Metals. 1969, N 4, p. 169-172.

13. L. Malerba, A. Caro, J. Wallenius. Multiscale modelling of radiation damage and phase transformations: The challenge of FeCr alloys // Journal of Nuclear Materials. 2008, v. 382, p. 112-125.

14. E.Z. Vintaykin, A.A. Loshmanov. About the nature of brittleness of $475^{\circ} \mathrm{C}$ of iron-chromium alloys // The Physics of Metals and Metallography. 1966, v. 22, N 3, p. 473-476.

15. E.Z. Vintaykin, Yu.V. Kolontsov. Aging IronChrome Alloys // The Physics of Metals and Metallography. 1968, v. 26, N 2, p. 282-288.

16. P. Grammatikopoulos, K. Nordlund. Molecular dynamics simulation of $\mathrm{Cr}$-precipitate demixing in $\mathrm{FeCr}$ alloys // Radiation Effects and Defects in Solids. 2014, v. 169, N 7, p. 646-654.

17. G. Bonny, P. Erhart, A. Caro, R.C. Pasianot, L. Malerba, and M. Caro. The influence of short range order on the thermodynamics of Fe-Cr alloys // Modeling Simul. Mater. Sci. Eng. 2009, v. 17, p. 025006 (16 p.).

18. I. Mirebeau, M. Hennion, G. Parette. First Measurement of Short-Range Order as a Function of Concentration in a Transition Alloy // Physical Review Letters. 1984, v. 53, N 7, p. 687-690.

19. I. Mirebeau and G. Parette. Neutron study of the short- range order inversion in $\mathrm{Fe} 1-x \mathrm{Cr} x / /$ Phys. Rev. B 82. 2010, p. 104203-1-104203-5.

20. V.I. Iveronova, A.A. Katznelson. Short-range order in solid solutions. M.: "Nauka", 1977, 255 p.

21. N.P. Filippova V.A. Shabashov, A.L. Nikolaev. Research of radiation-accelerated short-range ordering in binary Fe-Cr alloys by the NGR method // The Physics of Metals and Metallography. 2000, v. 90, N 30, p. 57-64.

22. V.L. Arbuzov, A.P. Druzhkov, S.M. Klotsman, A.L. Nikolaev, V.A. Tsurin, I.V. Altovsky, A.A. Grigoryan, S.V. Votinov. Effect of electron irradiation on the mechanical properties of iron-chromium alloys // Problems of Atomic Science and Technology. 1990, N 3(54), p. 58-61.

23. V.L. Arbuzov, S.M. Klotsman, A.L. Nikolaev, A.M. Sorokin, V.A. Zurin. Anomalies in the temperature dependence of near stratification in $\mathrm{Fe}-\mathrm{Cr}$ alloys under high-energy electron irradiation // Highly excited states in crystals. USSR Academy of Sciences SB (Tomsk Scientific Center). Tomsk, 1991, p. 40-46.

24. A.T. Adler, D.B. Rainford, J.S. Kouvel, T.J. Hicks. Ferromagnetism in iron-chromium alloys II Neutron scattering studies // Phys. Rev. B. 1976, v. 14, N 1, p. 228-234.

25. T. Ezawa, T. Akashi, R. Oshima. Damage structures and precipitation in electron-irradiated ironcromium alloys // J. Nucl. Mater. 1994, v. 212-215, p. 252-257.

26. W.Y. Chen, Y. Miao, Y. Wu, C.A. Tomchik, K. Mo, J. Gan, M.A. Okuniewski, S.A. Maloy, J.F. Stubbins. Atom probe study of irradiation-enhanced $\alpha^{\prime}$ precipitation in neutron-irradiated $\mathrm{Fe}-\mathrm{Cr}$ model alloys // J. Nucl. Mater. 2015, v. 462, p. 242-249. 
27. N.P. Kulish, P.V. Petrenko. Short-range Order in Binary Solid Solutions. Ordering and its Change at Heat in Fe-Al, Cu-Al and Ag-Al Alloys // Phys. Stat. Sol. (A). 1990, v. 120, N 1, p. 315-331.

28. N.P. Kulish, P.V. Petrenko, S.P. Repetskii, T.D. Shathiy. Coherent Potential Method in the Electronic Theory of Disordered Alloys // Phys. Stat. Sol. (B). 1991, v. 165, N 2, p. 143-156.

29. M. Bachhav, G.R. Odette, E.A. Marquis $\alpha^{\prime}$ precipitation in neutron-irradiated $\mathrm{Fe}-\mathrm{Cr}$ alloys // Scripta Materialia. 2014, v. 74, p. 48-51.

30. O. Tissot, C. Pareige, E. Meslin, B. Decamps, J. Henry. Kinetics of $\alpha^{\prime}$ precipitation in an electron irradiated $\mathrm{Fe} 15 \mathrm{Cr}$ alloy // Scripta Materialia. 2016, v. 122, p. 31-35.

31. J. Frost, K.K. Russell. Stability of exposure during irradiation. Phase transformations upon irradiation / Ed. F.V. Nolphy. Chelyabinsk: "Metallurgy", 1989, p. 188-194.

32. G.V. Lysova, G.A. Birzhevoy, N.P. Soloviev, M.I. Khramushin. A comparative analysis of the mechanisms of chromium segregation near the surface of the $\mathrm{Fe}-9 \mathrm{Cr}$ alloy and chromium ferritic-martensitic steel after irradiation with $\mathrm{He}+$ ions // Physics and Chemistry of Materials Processing. 2004, N 6, p. 10-13.

33. M.A. Vasiliev, A.M. Shalaev. Radiation and thermally stimulated segregation (review) // Metallophysics. 1988, v. 10, N 2, p. 64-72.

34. P.V. Petrenko, N.A. Melnikova, N.P. Kulish, Yu.E. Grabovsky, A.L. Gritskevich, I.V. Lebedev. The effect of electron irradiation on the nature of short range ordering in binary solid solutions // Metallophysics and Advanced Technologies. 1999, v. 22, N 11, p. 75-82.

35. P.V. Petrenko, N.A. Melnikova, N.P. Kulish, Yu.E. Grabovsky. The influence of short-range order on the vacancy absorption of solid / solutions // Problems of Atomic Science and Technology. 1999, N 3(75), p. 27-33.

36. P.V. Petrenko, N.P. Kulish, N.A. Melnikova, Yu.E. Grabovsky. The effect of correlation effects on radiation damage to solid solutions // The Physics of Metals and Metallography. 2016, v. 117, N 9, p. 959968.

37. D. Terentyev, P. Olsson. Aspectsof radiation damage effects in $\mathrm{Fe}-\mathrm{Cr}$ alloys the point of view of atomistic modeling // Problems of Atomic Science and Technology. 2009, N 4-1(94), p. 68-79.

Статья поступила в редакциию 15.09.2020 2.

\title{
БЛИЖНИЙ ПОРЯДОК И ЕГО ВЛИЯНИЕ НА РАДИАЦИОННУЮ СТОЙКОСТЬ НИЗКОКОНЦЕНТРАЦИОННЫХ СПЛАВОВ $\mathrm{Fe}-\mathrm{Cr}$
}

\author{
П.В. Петренко, Н.П. Кулиш, Н.А. Мельникова, Ю.Е. Грабовский, Т.О. Буско
}

Проанализировано на мезоскопическом уровне структурно-фазовое состояние низкоконцентрационных твердых растворов $\mathrm{Fe}-\mathrm{Cr}$ и стали $1 \mathrm{X} 13$ в связи с образованием в них ближнего порядка различных типов. Проведено сравнение степени ближнего порядка и величины распухания сплавов при облучении. Показано, что между ними наблюдается довольно хорошая качественная корреляция.

\section{БЛИЗЬКИЙ ПОРЯДОК ТА ЙОГО ВПЛИВ НА РАДІАЦІЙНУ СТІЙКІСТЬ НИЗЬКОКОНЦЕНТРАЦІЙНИХ СПЛАВІВ Fе-Сr}

\author{
П.В. Петренко, Н.П. Куліш, Н.А. Мельникова, Ю.С. Грабовський, Т.О. Буско
}

Проаналізовано на мезоскопічному рівні структурно-фазовий стан низькоконцентраційних твердих розчинів $\mathrm{Fe}-\mathrm{Cr}$ та сталі 1X13 у зв'язку з утворенням у них близького порядку різних типів. Проведено порівняння ступеня близького порядку та величини розпухання сплавів при опроміненні. Показано, що між ними має місце досить добра якісна кореляція. 